\title{
ANÁLISE ESPACIAL DA COBERTURA VEGETAL NO CENTRO URBANO DO MUNICÍPIO DE SALTO DE PIRAPORA (SP)
}

\author{
Daiane Maiara da Silva \\ Universidade de Sorocaba, Sorocaba, SP, Brasil \\ daiane.msilva93@gmail.com \\ Glauber Grandine \\ Universidade de Sorocaba, Sorocaba, SP, Brasil \\ glauber.grandine@hotmail.com \\ Vanessa Cezar Simonetti \\ Universidade Estadual Paulista (Unesp), Instituto de Ciência e Tecnologia, Sorocaba, SP, Brasil \\ va simonetti@hotmail.com \\ Darllan Collins da Cunha e Silva \\ Universidade Estadual Paulista (Unesp), Câmpus Experimental de Registro, SP, Brasil \\ darllanamb@yahoo.com.br
}

\begin{abstract}
RESUMO
A vegetação possui grande importância ao que tange a qualidade ambiental dos espaços urbanos, promovendo serviços ecossistêmicos que amplificam a qualidade de vida da população. Nesse sentido, o estudo analisou a cobertura vegetal do município de Salto Pirapora (SP), a partir da elaboração de um índice de cobertura vegetal (ICV) por setor censitário e por habitante (ICVH), sendo ambos correlacionados com os parâmetros preconizados pela Organização das Nações Unidas (ONU), que sugere um índice de $12 \mathrm{~m}^{2}$ de cobertura vegetal por habitante em áreas urbanas. Como procedimento metodológico para extração da vegetação, foi utilizado a composição falsa-cor por meio de imagens de satélite Landsat-8; no entanto, para melhor acurácia, foi realizado o fusionamento digital de imagens pancromáticas com resolução espacial de $15 \mathrm{~m}$. Como resultado, dos 37 setores censitários da zona urbana, 28 setores (76\%) não apresentaram os valores de cobertura vegetal sugeridos por habitante, e somente 9 setores censitários (24\%) atenderam ao índice. Ainda, foi possível verificar que a densidade demográfica possui uma relação diretamente proporcional aos índices de cobertura vegetal. Portanto, estudo inferiu sobre aspectos quantitativos da vegetação, evidenciando a necessidade da ampliação das áreas verdes da região central do município de Salto de Pirapora.
\end{abstract}

Palavras-chave: Áreas Verdes. Geoprocessamento. Sensoriamento Remoto. Vegetação. Censo Demográfico. Índices.

\section{SPATIAL ANALYSIS OF VEGETATION COVERAGE IN THE URBAN CENTER OF SALTO DE PIRAPORA COUNTY, SÃO PAULO STATE, BRAZIL}

\begin{abstract}
The vegetation has great importance to the environmental quality of urban spaces, promoting ecosystem services that amplify the quality of life of the population. In this sense, the study analyzed the vegetation cover of the city of Salto de Pirapora (SP), based on the elaboration of a vegetation cover index ( $\mathrm{VCl}$ ) by census and per capita sector, both correlated with the parameters recommended by the Organization of the United Nations (UN), which suggests an index of $12 \mathrm{~m}^{2}$ of vegetation cover per inhabitant in urban areas. As a methodological procedure for vegetation extraction, the false-color composition was used by Landsat-8 satellite images; however, for better accuracy, the digital fusion of panchromatic images with spatial resolution of 15 meters was carried out. As a result, of the 37 census tracts in the urban area, 28 sectors $(76 \%)$ did not present the vegetation cover values suggested per inhabitant, and only 9 census tracts $(24 \%)$ attended the index. Also, it was possible to verify that the population density has a relation directly proportional to the indices of vegetal cover. Therefore, the study inferred on quantitative aspects of the vegetation, evidencing the necessity of the enlargement of the green areas of the central region of the municipality of Salto de Pirapora.
\end{abstract}

Keywords: Green Areas. Geoprocessing. Remote Sensing. Vegetation. Demographic Census. Indexes. 


\section{INTRODUÇÃO}

A vegetação possui grande importância no que se refere à qualidade do meio ambiente e a manutenção da vida na terra, onde sua finalidade é preservar os recursos hídricos, conservar a diversidade de plantas e animais, conquistando assim, os espaços urbanos brasileiros (GOMES, 2003; NUCCI, 2001; ALVES et al., 2011; CABRAL, 2013).

Segundo Cabral (2013), a vegetação é um elemento essencial que promove benefícios à saúde de toda população terrestre, estabelecendo um equilíbrio da temperatura ambiente, mantendo a umidade do ar e promovendo sombra nos dias ensolarados, tornando assim mais amena a vivência, melhorando a saúde física e mental de toda a população.

Nas cidades, a vegetação desempenha inúmeras funções, servindo de abrigo à fauna silvestre, melhorando a qualidade do ar e da água, atuando como barreiras contra o vento, reduzindo os ruídos emitidos, auxiliando no equilíbrio da umidade do ar e da temperatura dos espaços urbanos (NUCCl, 2001; LIMA e AMORIM, 2011; LOURENÇO et al., 2014).

Diversos elementos influenciam na qualidade ambiental dos espaços urbanos; sendo assim, a necessidade de buscar novas tecnologias é imprescindível. Para tanto, softwares cada vez mais sofisticados têm possibilitado o uso de imagens de satélite para variados fins, principalmente aos que tangem o planejamento, monitoramento ambiental e mapeamento de vastas áreas. Ainda, as inovações concernentes ao geoprocessamento têm possibilitado a realização de uma vasta gama de análises espaciais e temporais (LANG e BLASCHKE, 2009; LIMA e AMORIM, 2011; OLIVEIRA et al., 2016; FARIA e TEIXEIRA, 2017).

A observação da vegetação a partir de imagens orbitais e sistemas de informações geográficas (SIG) fornecem informações sobre diversos aspectos da paisagem, sendo amplamente utilizada (ALEXANDRIDIS et al., 2014). Os SIG são compostos por ferramentas bastante complexas que permitem a integração de um vultoso volume de dados de natureza e escalas distintas (LANG e BLASCHKE, 2009; SALES et al., 2016; VALLE et al., 2016).

Nesse sentido, diversos trabalhos vêm sendo desenvolvidos sobre a importância da análise de cobertura vegetal, tais como o realizado por Nery et al. (2014), que monitorou o comportamento espectral de uma área desmatada no município de Rio Pardo (MG), utilizando dados de sensores orbitais e técnicas de processamento digital de imagens permitindo assim, a detecção estrutural da vegetação bem como as mudanças ocorridas na área antes e depois da supressão da vegetação.

Todavia, Buccheri Filho e Nucci (2011) utilizaram um índice de cobertura vegetal para avaliar a vegetação no Bairro Alto da XV, do município de Curitiba (PR), encontrando um índice de cobertura vegetal igual a $16,85 \%$, ressaltando assim, que as áreas verdes e a cobertura vegetal são elementos fundamentais para um planejamento urbano que se preocupa com a qualidade ambiental do município.

Estudos realizados por Alves et al. (2011) avaliaram diferentes tipologias construtivas e a influência da vegetação no clima urbano de uma importante avenida da cidade de Salvador (BA) e constataram a formação de ilhas de calor nas tipologias mais adensadas da avenida.

Entretanto, o entendimento da intrínseca relação do homem e o ambiente é importante ao que tange o planejamento urbano e ambiental. Para tanto, o auxílio de geotecnologias vem contribuindo na identificação e quantificação das estruturas espaciais e na compreensão dos fenômenos que ocorrem no espaço (MEIRA et al., 2016; OLIVEIRA et al., 2016; FARIA e TEIXEIRA, 2017).

Visto isso, o presente estudo analisou a cobertura vegetal presente no município de Salto Pirapora (SP) a partir de um índice de cobertura vegetal por setor censitário com o intuito de fornecer subsídios para o planejamento e correlacionar essas áreas verdes existentes no município com o número de habitantes de cada setor censitário, utilizando, para isso, conceitos, técnicas e procedimentos inerentes ao geoprocessamento.

\section{METODOLOGIA}

\section{Caracterização da área de estudo}

A área de estudo está inserida no município de Salto de Pirapora (Figura 1), que se localiza na Região Metropolitana de Sorocaba (RMS) e possui extensão territorial de aproximadamente $280,7 \mathrm{~km}^{2} \mathrm{com}$ uma população de 44.397 habitantes, conforme estimativa do Instituto Brasileiro de Geografia e Estatística

\begin{tabular}{llllll}
\hline Caminhos de Geografia & Uberlândia - MG & v. 19, n. 68 & Dez/2018 & p. 361-371 Página 362
\end{tabular}


(IBGE, 2017). Salto de Pirapora faz limite com os municípios de Araçoiaba da Serra, Sarapuí, Pilar do Sul, Piedade, Votorantim e Sorocaba.

Figura 1: Mapa de localização do município de Salto de Pirapora

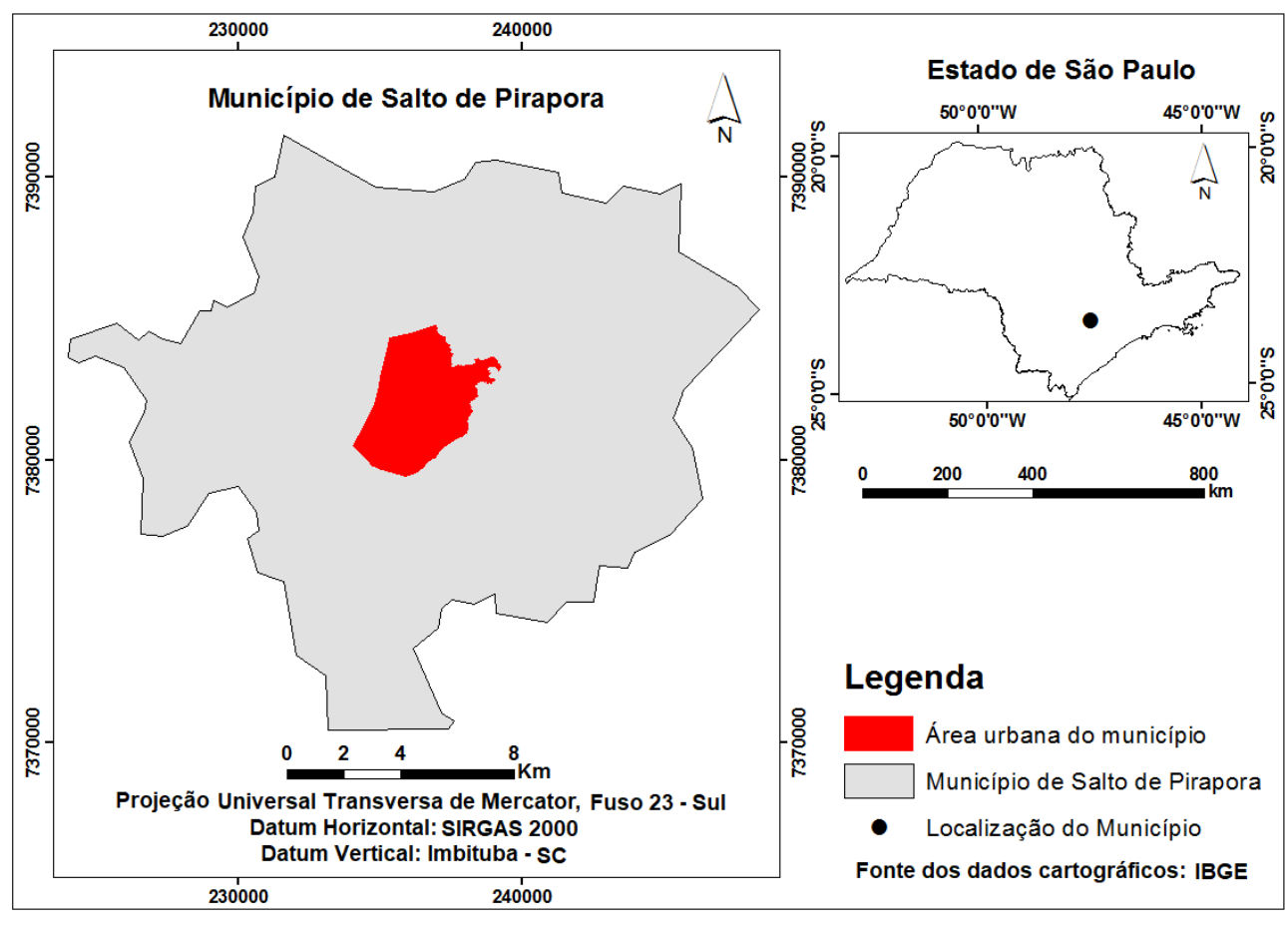

Elaborado pelos autores

Segundo a classificação de Köppen-Geiser, o clima local, é classificado como pertencente ao domínio de clima Subtropical (Cwa). A temperatura média fica em torno de 22,5으. C. Do ponto de vista geológico, a região situa-se numa faixa de transição do Planalto Atlântico para a Depressão Periférica, apresentando rochas metamórficas e ígneas do embasamento cristalino, rochas sedimentares e rochas extrusivas e intrusivas básicas pertencentes à Bacia Sedimentar do Paraná, além de sedimentos cenozoicos (LOURENÇO et al., 2014; OLIVEIRA et al., 2016; SALES et al. 2016).

O Município de Salto de Pirapora é banhado pelos Rios Sarapuí (afluente do Rio Sorocaba, onde desemboca nas divisas entre Tatuí e Iperó) e o Rio Pirapora (principal afluente do Rio Sarapuí, que se encontram no extremo oeste do município). Está inserido na Unidade de Gerenciamento de Recursos Hídricos (UGHRI-10), denominada Sorocaba-Médio Tietê, pertencendo à sub-bacia do Baixo Sorocaba, possuindo uma área de $3.136 \mathrm{~km}^{2}$ (SIGRH, 2013)

O município possui um elevado dinamismo em suas atividades urbanas, apresentando taxas de urbanização superiores às médias da sub-bacia, com cerca de $80 \%$. Na agricultura, destaca-se o cultivo de feijão e milho. O município também é um importante produtor de areia e calcário para construção civil (SIGRH, 2013).

\section{Aquisição dos dados cartográficos e geoespaciais}

Para realização desse estudo foi utilizado o limite cartográfico do município de Salto de Pirapora, disponibilizado pelo Instituto Brasileiro de Geografia Estatística (IBGE), sendo que essa base cartográfica foi utilizada para recortar as imagens do Landasat-8 disponibilizadas pelo Serviço Geológico Americano (United States Geological Survey - USGS) na órbita 220 e ponto 76. As imagens são do dia 17 de fevereiro de 2017, abrangendo o limite municipal de Salto de Pirapora. 


\section{Classificação das imagens orbitais para obtenção das áreas com vegetação}

Foram geradas composições de bandas falsa-cor para realçar a vegetação com a combinação da Banda 5 - Infravermelho Próximo, 4 - Visível Vermelho e 3 - Visível Verde. Posteriormente, foi realizado o fusionamento de imagens, através da fusão banda PAN (tons de Cinza) de 15 metros de resolução espacial com as bandas multiespectrais (coloridas) de $30 \mathrm{~m}$, a fim de garantir a resolução espacial final da cena com $15 \mathrm{~m}$.

Essa imagem foi submetida a uma classificação supervisionada que teve como objetivo associar cada pixel da imagem a um padrão, descrevendo as áreas com presença de vegetação. Para tanto, foi utilizado o método de classificação supervisionado de Máxima Verossimilhança (MAXVER), sendo selecionadas as amostras de treinamentos mais representativas das classes a serem mapeadas, sendo que o agrupamento foi realizado automaticamente pelo sistema, o qual identificou as nuvens de pixels que apresentam respostas espectrais semelhantes às amostras selecionadas, no caso do classificador paramétrico MAXVER, este classifica os agrupamentos de pixels considerando a ponderação das distâncias entre as médias dos níveis digitais de classe definida na seleção (OLIVEIRA et al., 2016; SILVA et al., 2016). Posteriormente, esses dados foram vetorizados possibilitando assim o cálculo de cada feição da vegetação identificada.

\section{Elaboração do Índice de Cobertura Vegetal (ICV)}

Após o mapeamento da cobertura vegetal, calculou- se o índice de cobertura vegetal por setor censitário através da Equação (1), proposta por Silva (2016):

$$
\mathrm{ICV}=\frac{\mathrm{CVSC}}{\mathrm{ASC}}
$$

Sendo:

ICV é o valor do índice de cobertura vegetal para cada setor censitário;

CVSC é a área, em m², de cobertura vegetal presente em cada setor censitário; e

ASC é a área, em $\mathrm{m}^{2}$, de cada setor censitário.

Os valores obtidos de ICV foram correlacionados com os parâmetros determinados pela Organização das Nações Unidas - ONU (Quadro 1) que sugere um índice acima de 30\% de cobertura vegetal em áreas urbanas como de alta qualidade ambiental e, caso seja inferior a 5\%, como de baixa qualidade ambiental e semelhante a regiões desérticas (BORGES et al., 2012).

Quadro 1: Índice de cobertura vegetal, segundo parâmetros da Organização das Nações Unidas (ONU)

\begin{tabular}{|ll|}
\hline \multicolumn{2}{|c|}{ ÍNDICE DE COBERTURA VEGETAL (ICV) } \\
\hline Condição Boa & $\begin{array}{l}\text { Residentes em áreas com cobertura vegetal } \\
\text { suficiente para garantir uma qualidade de vida alta } \\
\text { (ICV }>30 \%) .\end{array}$ \\
\hline Condição Regular & $\begin{array}{l}\text { Residentes em áreas com cobertura vegetal } \\
\text { suficiente para garantir uma qualidade de vida } \\
\text { razoável }(5 \%<I C V<30 \%) .\end{array}$ \\
\hline Condição Ruim & $\begin{array}{l}\text { Residentes em áreas com cobertura vegetal } \\
\text { insuficiente para garantir uma qualidade de vida } \\
\text { razoável (ICV }<5 \%) .\end{array}$ \\
\hline
\end{tabular}

Adaptado de SILVA (2016, p. 84)

Ressalta-se que para a adoção dos parâmetros propostos pela ONU não se diferenciou as áreas urbanas e rurais, porém nas áreas rurais do município de Salto de Pirapora verificou-se uma presença mais expressiva de áreas com coberturas vegetais e, portanto, seus índices de cobertura vegetal são altos. Contudo, pelo fato das áreas rurais possuírem uma ampla variedade de culturas agrícolas que não foram objeto deste estudo, e por não apresentarem os aspectos concernentes ao

\begin{tabular}{llllll}
\hline Caminhos de Geografia & Uberlândia - MG & v. 19, n. 68 & Dez/2018 & p. 361-371 & Página 364
\end{tabular}


lazer, recreação e paisagismo, buscou-se analisar mais detalhadamente a zona urbana que sofreu intensa intervenção antrópica desde a fundação do município.

Calculou-se, também, o índice de cobertura vegetal por habitante, baseado no mapa de vegetação e nos dados populacionais disponibilizados pelo censo demográfico do IBGE. Para isso, foi estimada a população presente nos setores censitários de 2010, referente ao ano de 2017 , com base no percentual de crescimento municipal de 2010 para 2017 que foi de 10,63\% e aplicando esse percentual de crescimento a cada setor censitário.

Para calcular o índice de cobertura vegetal por habitante foi utilizada a Equação (2):

$$
\mathrm{ICVH}=\frac{\Sigma \mathrm{CV}}{\mathrm{H}}
$$

Sendo:

ICVH = Índice de Cobertura Vegetal;

$\Sigma \mathrm{CV}=$ Somatório da Cobertura Vegetal; e

$\mathrm{H}=$ № de habitantes estimado para 2017 por setor censitário.

O mapeamento, a quantificação da vegetação por setor censitário e por habitante e os outros itens da cobertura do solo bem como seus respectivos layouts, foram realizados com a utilização do software ArcGIS 10.4.1.

\section{RESULTADOS E DISCUSSÃO}

A partir da composição falsa-cor foram segmentadas as áreas com vegetação no município de Salto de Pirapora e diferenciá-la das demais feições. A Figura 2 apresenta o mapa com a cobertura vegetal do município presente em cada setor censitário.

Figura 2: Cobertura vegetal do município de Salto de Pirapora (SP)

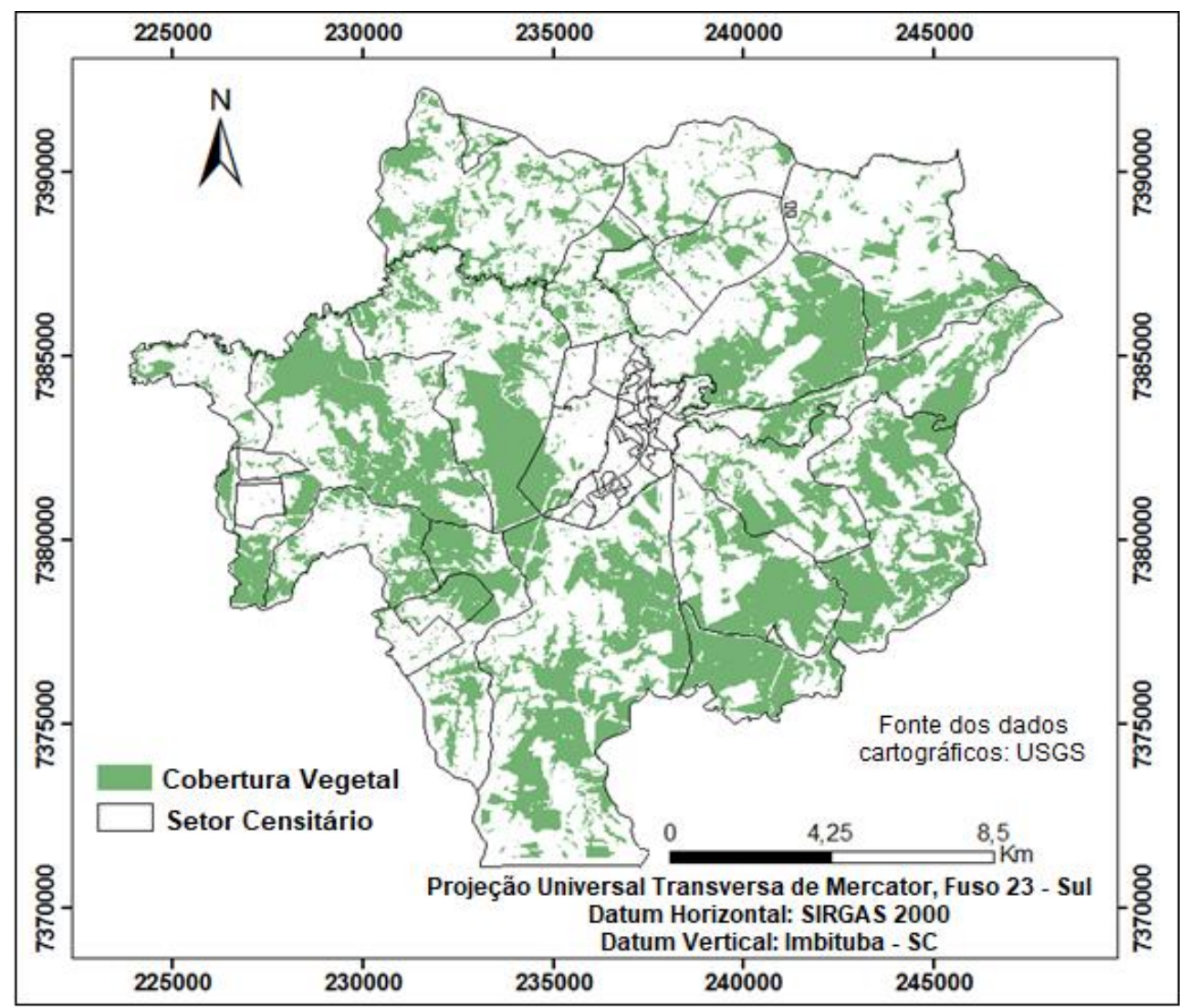

Elaborado pelos autores 
No município de Salto de Pirapora foram identificados 61 setores censitários, sendo 37 da zona urbana, e 24 na zona rural. Através da caracterização da cobertura vegetal do município foi possível observar que a zona rural possui quantidade significativa de área verde; no entanto, essas áreas não foram abordadas nesse estudo como benéficas e mantenedoras da qualidade ambiental devido a diversidade de unidades de produção agropecuária cujo papel ecossistêmico para a fauna depende das práticas de manejo sustentáveis que não foram objetos deste estudo.

Segundo Simonetti et al. (2018), quando não se dispõe de práticas de cultivos agrícolas adequadas ao que tange o manejo e conservação do solo, podem ocorrer danos ambientais que favorecem a perda de solos bem como o assoreamento dos cursos d'agua.

Entretanto, os resultados relevaram que o município possui $39,51 \%$ de cobertura, sendo $38,78 \%$ na zona rural, e $0,72 \%$ na zona urbana o que representa aproximadamente $110,9 \mathrm{~km}^{2}$ de cobertura vegetal arbórea (Figura 2). Portanto, a zona urbana apresentou valores de cobertura vegetal consideravelmente baixo.

A Figura 3 representa o índice de cobertura vegetal (ICV) dos setores censitários segundo os parâmetros estabelecidos pela ONU (Quadro 1). A área apresentou valores de índice de cobertura vegetal (ICV) recomendados pela ONU, ou seja, acima de 30\%. Entretanto, a população que reside nas zonas rurais é significativamente menor em relação às pessoas residentes nas zonas urbanas, fato que se reverbera na maioria dos municípios brasileiros.

Figura 3: Índice de Cobertura Vegetal (ICV) por setor censitário

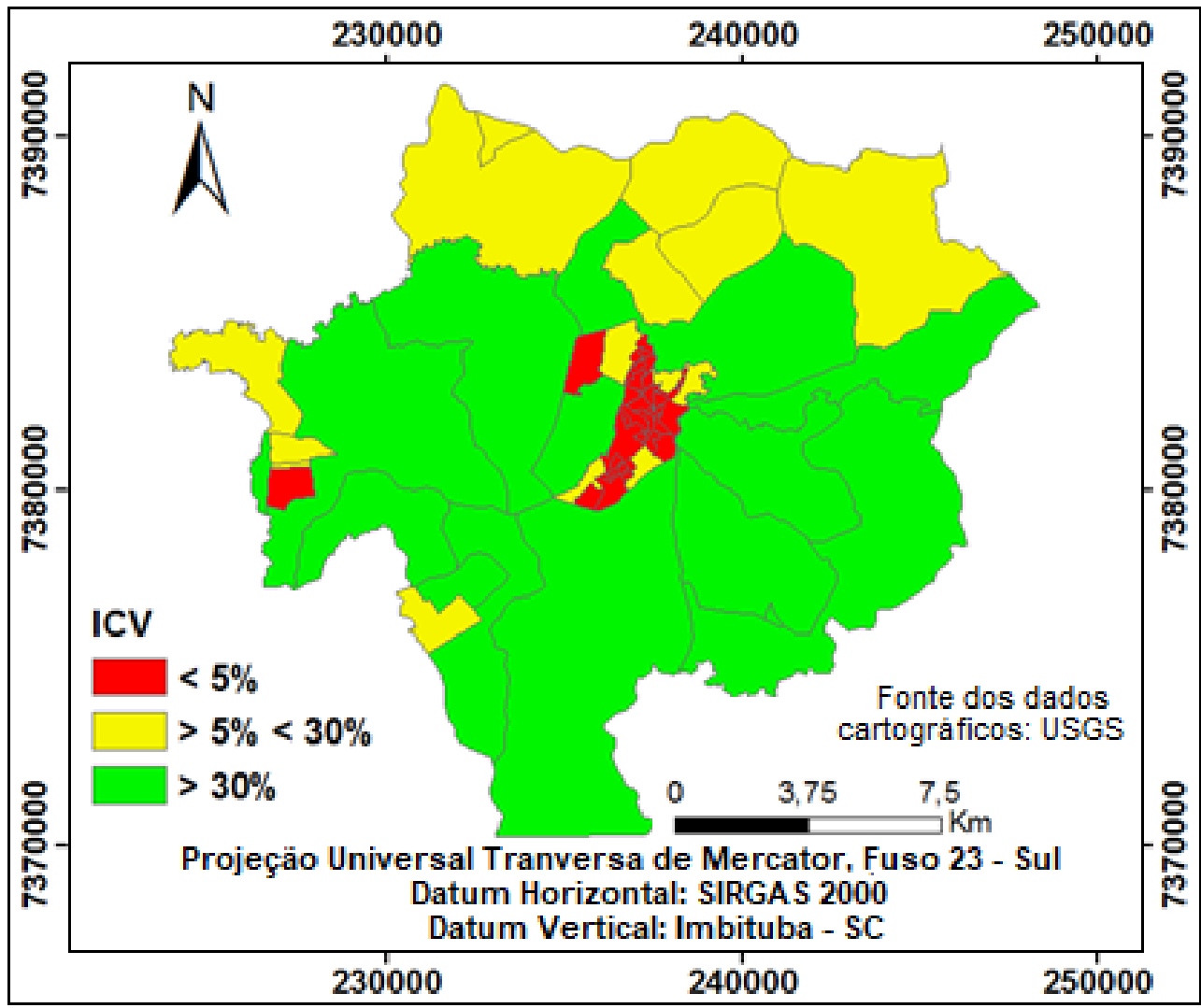

Elaborado pelos autores

Segundo dados fornecidos pelo IBGE (2010), a população residente na zona rural do município é de apenas 8.669 habitantes, enquanto a estimativa populacional de habitantes do município para 0 ano de 2017 é de 44.397 habitantes. Levando em consideração o fato da maior parcela da população residir na zona urbana, é possível inferir sobre a forte pressão antrópica nos recursos naturais do município, principalmente ao que tange os fragmentos florestais. A Figura 4 expressa a cobertura vegetal presente no centro urbano de Salto de Pirapora. 
Figura 4: Índice de Cobertura Vegetal (ICV) da Zona Urbana do município de Salto de Pirapora

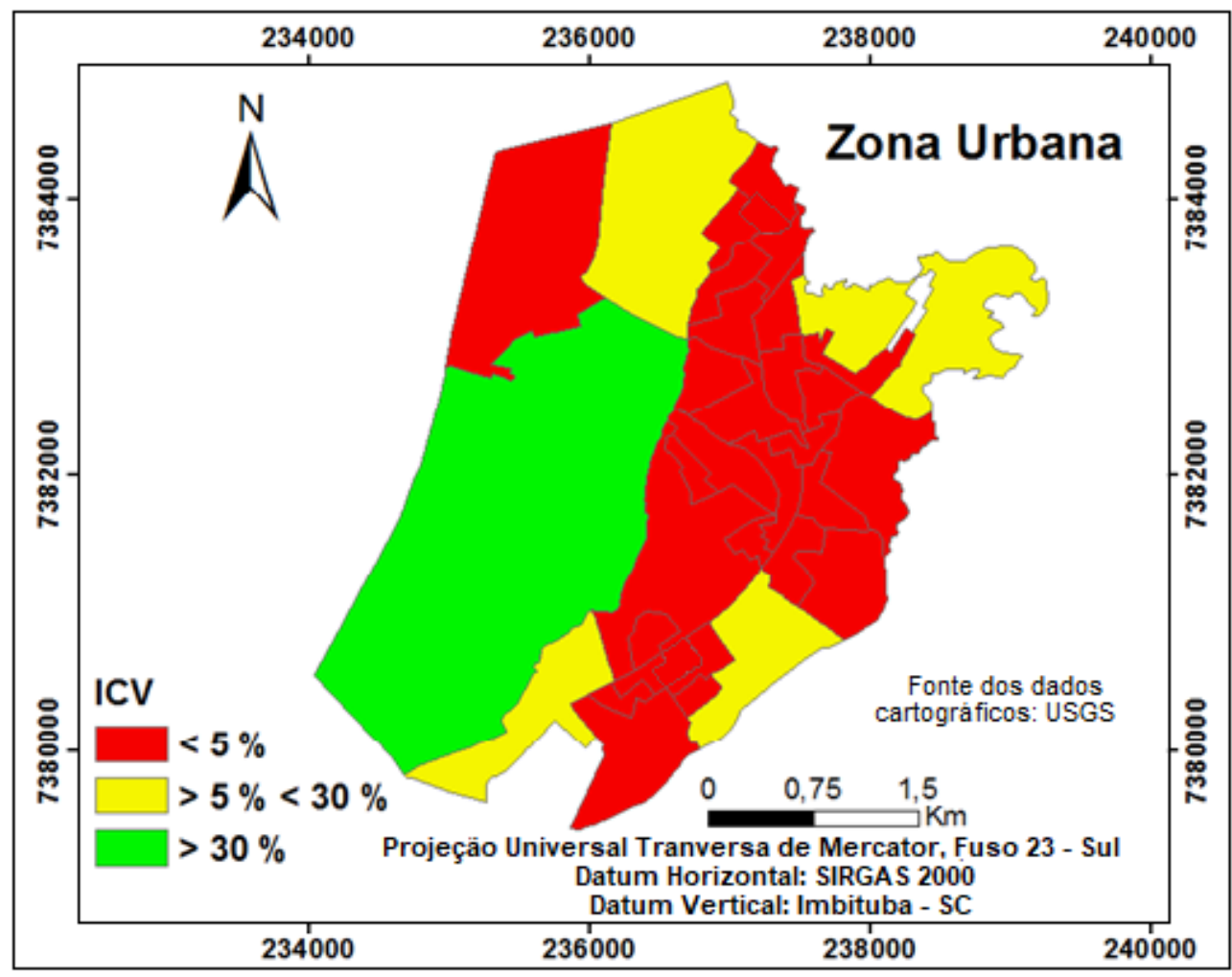

Elaborado pelos autores

Foram identificados nove setores censitários (24\%), dos 37 da zona urbana, que atendem aos índices sugeridos pelas organizações supracitadas, sendo que o maior valor encontrado no estudo foi de $112,4 \mathrm{~m}^{2}$ de área verde por habitante. No entanto, a zona urbana apresenta valores caracterizados, segundo Nucci (2001), como desertos florísticos, ou seja, áreas que variam da ausência total de vegetação ou que possuem percentual inferior a 5\%. Ainda, segundo o autor, a mensuração dos índices que tratam das áreas verdes devem contemplar somente as áreas públicas das zonas urbanas e devem estar diretamente ligadas ao uso da população. Estudos realizados por Duarte et al. (2017) avaliaram a influência da cobertura vegetal nos ambientes urbanos, abordando esses espaços como ecossistemas urbanos do qual os seres humanos são organismos integrantes de um complexo sistema.

Os baixos índices de cobertura vegetal encontrados na zona urbana fazem parte do cenário de expansão urbana vivenciada pelo país desde a segunda metade do século XX, que contribuiu com o povoamento das cidades de forma bastante acelerada e desordenada (GOMES e QUEIROZ, 2011; CARDOZO e ARRUDA, 2016).

Liu et al. (2014) avaliaram os níveis de urbanização global estabelecendo uma estrutura hierárquica para definir os níveis de urbanização, inferindo que as áreas urbanas globais para o ano de 2010 atingiram $3 \%$. Segundo os autores, o conhecimento das áreas urbanizadas pode auxiliar na compreensão dos impactos biofísicos, sociais e econômicos decorrentes desse processo.

Impulsionadas pelo advento da industrialização, as cidades perderam suas áreas de matas numa velocidade avassaladora, levando biomas, como o Cerrado e Mata Atlântica, a perderem grande parte de sua biodiversidade. Na tentativa de reestabelecer o equilíbrio ambiental, diversos estudos estão sendo realizados com o intuito de quantificar as áreas verdes remanescentes dos ambientes urbanos. De acordo com o estudo realizado por Borges et al. (2012), a ONU (Organização das Nações Unidas), a OMS (Organização Mundial da Saúde) e a FAO (Organização das Nações Unidas para Agricultura e Alimentação) no Brasil, recomendam que cada habitante disponha de $12 \mathrm{~m}^{2}$ de área verde, sendo este um valor adequado para que as áreas verdes forneçam os serviços ecossistêmicos e contribuam para o desenvolvimento das atividades do homem.

$\begin{array}{llllll}\text { Caminhos de Geografia } & \text { Uberlândia - MG } & \text { v. 19, n. } 68 & \text { Dez/2018 } & \text { p. 361-371 } & \text { Página } 367\end{array}$


Para tanto, de modo a verificar o índice de cobertura vegetal por habitante (ICVH), conforme as recomendações supracitadas, cujo índice é de $12 \mathrm{~m}^{2}$ por habitante, foi confeccionado o mapa de ICVH da zona urbana, conforme a Figura 5.

Figura 5: Índice de Cobertura Vegetal por Habitante (ICVH) da Zona Urbana do Município de Salto de Pirapora

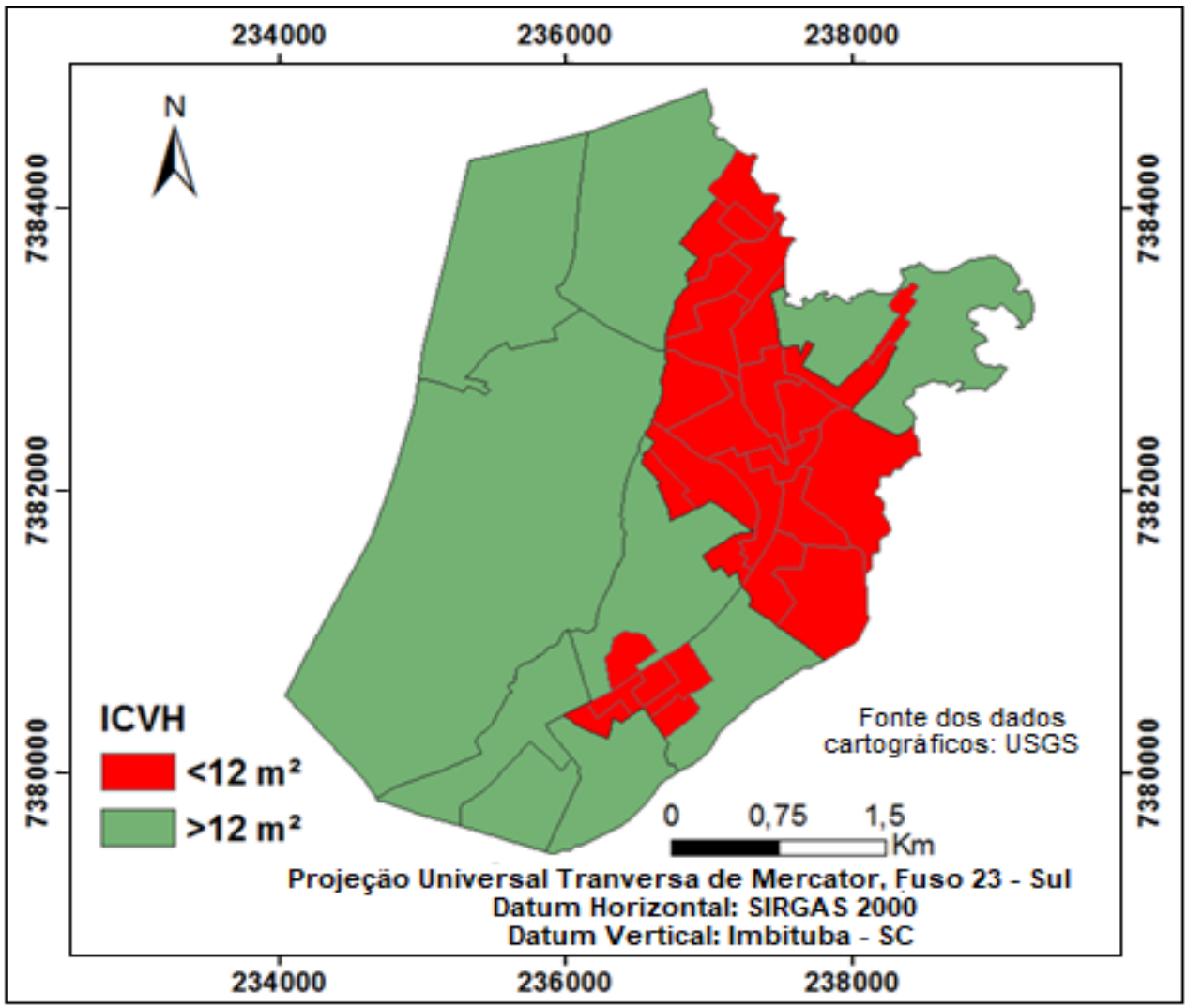

Elaborado pelos autores

A partir do ICVH foi possível inferir que, dentre os 37 setores censitários da zona urbana, 28 setores, ou seja, $76 \%$ não apresentam $12 \mathrm{~m}^{2}$ de cobertura vegetal por habitante, 9 setores censitários $(24 \%)$ atendem ao índice, superando o padrão estabelecido. Dentre os setores censitários presentes no perímetro urbano, houve um setor que registrou $1702,6 \mathrm{~m}^{2}$ de cobertura vegetal, ou seja, um número 142 vezes superior ao limite mínimo recomendado.

Estudos realizados por Costa e Ferreira (2007), no município de Juiz de Fora (MG), também utilizaram o índice de vegetação na zona central para análise quantitativa da vegetação e sua distribuição espacial. Os autores analisaram 26 regiões urbanas (RUS) do município e obtiveram um índice de área verde (IAV) igual a 0 em 13 regiões. Os maiores índices encontrados pelos autores foram de $18 \mathrm{~m}^{2}$ e $35 \mathrm{~m}^{2}$ por habitante, ou seja, somente dois setores atenderam aos parâmetros recomendados pela OMS. De modo geral, metade das RUS investigadas pelos autores não apresentaram um IAV satisfatório, capaz de promover os benefícios inerentes à vegetação e seus serviços ecossistêmicos.

No entanto, a redução de áreas verdes nos centros urbanos pode resultar no surgimento de ilhas de calor. Estudos realizados por Alves et al. (2011) identificaram esse fenômeno em determinadas áreas inseridas na em uma avenida que representa um importante eixo de expansão do município de Salvador (BA). O estudo revelou a formação de possíveis ilhas de calor nas tipologias mais adensadas da região que possuíam um elevado grau de impermeabilização do solo. Ortiz e Amorim (2011) também analisaram o clima urbano decorrente das mudanças da cobertura da superfície urbana do município de Cândido Mota (SP), constatando o aumento da temperatura nas zonas urbanas se comparado com os ambientes rurais.

$\begin{array}{llllll}\text { Caminhos de Geografia } & \text { Uberlândia - MG } & \text { v. 19, n. } 68 & \text { Dez/2018 } & \text { p. 361-371 } & \text { Página } 368\end{array}$


Nesse sentido, a perda de vegetação e a impermeabilização do solo aumentam o risco de inundação das áreas mais suscetíveis à ocorrência desse fenômeno. A ocupação de áreas de várzeas, o desmatamento para atender à especulação imobiliária, como exemplo; podem agravar e intensificar essas ocorrências. Sendo assim, Cardozo e Arruda (2016) avaliaram as áreas de risco da bacia hidrográfica do Córrego do Ourives, pertencente à área urbana do município de Salto de Pirapora. Os autores identificaram diversos impactos ambientais na área de estudo ocasionadas, sobretudo, pelo processo de urbanização inadequada.

Todavia, os resultados encontrados por Cardozo e Arruda (2016) corroboram os resultados obtidos no presente estudo, que identificou um menor índice de cobertura vegetal nos setores censitários pertencentes à zona urbana, onde $76 \%$ dos setores não apresentaram índices de cobertura vegetal satisfatórios, ou seja, abaixo de $5 \%$.

A ausência de cobertura vegetal e áreas verdes podem interferir em diversos aspectos do ambiente, comprometendo a qualidade de vida população, pois estas exercem não somente funções ecológicas, mas também recreativas, estéticas e econômicas (GOMES e QUEIROZ, 2011).

Os resultados alcançados revelaram que a análise e o mapeamento do índice de cobertura vegetal por setor censitário bem como a correlação com a população do município de Salto de Pirapora para o ano de 2017, por meio de técnicas de geoprocessamento e imagens orbitais, constitui uma técnica bastante eficiente para o estudo e monitoramento dos espaços geográficos, fornecendo informações bastante relevantes ao que tange a vegetação presente nos espaços urbanos e suas possíveis implicações na qualidade ambiental, refletindo assim, na qualidade de vida da população.

\section{CONSIDERAÇÕES FINAIS}

O estudo inferiu sobre aspectos quantitativos da vegetação, evidenciando a necessidade da ampliação das áreas verdes, principalmente na área central do município de Salto de Pirapora. As áreas rurais contempladas no estudo apresentaram valores superiores se comparadas às áreas verdes urbanas.

A metodologia utilizada foi bastante satisfatória, proporcionando um amplo entendimento da distribuição espacial da cobertura vegetal do município de Salto de Pirapora, podendo auxiliar no monitoramento das áreas verdes em longo prazo, podendo, ainda, ser replicado na gestão e monitoramento de outros municípios.

Embora os ambientes urbanos influenciem consideravelmente na qualidade ambiental devido os impactos que causam, os estudos que contemplem a ecologia urbana das cidades e suas intrínsecas relações bióticas e abióticas são incipientes. Os ambientes urbanos crescem consideravelmente em todo o mundo, uma vez que a população busca esses espaços para consolidação de seu modo de vida, pois encontram uma infinidade de recursos nesses ambientes. Deste modo, o conhecimento das áreas verdes dos centros urbanos por meio de índices ou indicadores constitui um importante ponto de partida para estudos mais aprofundados. É importante salientar que os estudos que tratam dos índices de áreas verdes nos centros urbanos são importantes, porém, é necessário inferir sobre a qualidade da vegetação desses espaços, uma vez que as espécies arbóreas possuem diferenças significativas no tocante aos serviços ecossistêmicos que desempenham.

Em razão da importância da vegetação no tocante aos serviços ambientais inerentes que refletem na qualidade ambiental, recomenda-se o acompanhamento da evolução da cobertura vegetal do município de Salto de Pirapora. Para tanto, a utilização de ferramentas de geoprocessamento, como sistemas de informação geográfica (SIG) e sensoriamento remoto (SR) podem contribuir significativamente na avaliação e monitoramento desses espaços.

Este estudo serve de subsídios à gestão pública do município para que sejam realizadas ações que contemplem o reflorestamento das áreas urbanas com maior déficit de vegetação, resultando, assim, na promoção de melhorias à qualidade de vida da população e da fauna silvestre que habitam essas áreas.

\section{REFERÊNCIAS}

ALEXANDRIDIS, T. K.; OIKONOMAKIS, N.; GITAS, I. Z.; ESKRIDGE, K. M.; SILLEOS, N. G. The performance of vegetation indices for operational monitoring of CORINE vegetation types. International

\begin{tabular}{llllll}
\hline Caminhos de Geografia & Uberlândia - MG & v. 19, n. 68 & Dez/2018 & p. 361-371 & Página 369
\end{tabular}


Journal of Remote Sensing, v. 35, n. 9, p. 3268-3285, 2014. Disponível em: <https://doi.org/10.1080/01431161.2014.902548>. Acesso em: 10 dez. 2017.

ALVES, A. C. N.; DE ANDRADE, T. C. Q.; NERY, J. M. F. G. A influência da vegetação e da ocupação do solo no clima urbano: um exercício analítico sobre a Avenida Paralela. Fórum Patrimônio: Ambiente Construído e Patrimônio Sustentável, v. 4, n. 1, p. 43-52, 2011.

BORGES, C. A. R. F.; MARIM, G. C.; RODRIGUES, J. E C. Mapeamento da cobertura vegetal do bairro da Marambaia-Belém/PA. REVSBAU, v. 7, n. 4, p.16-26, 2012.

BUCCHERI FILHO, A. T.; NUCCI, J. C. Espaços livres, áreas verdes e cobertura vegetal no bairro Alto da XV, Curitiba/PR. Revista do departamento de Geografia, v. 18, p. 48-59, 2011. Disponível em: <http://dx.doi.org/10.7154/RDG.2006.0018.0005>. Acesso em: 16 nov. 2017.

CABRAL, P. I. D. Arborização urbana: problemas e benefícios. Revista Especialize On-line IPOG, v. 1, n. 6, 2013.

CARDOZO, M. C.; ARRUDA, E. M. Análise ambiental e ocupação de áreas de risco na bacia do córrego dos ourives, Salto de Pirapora-SP. OBSERVATORIUM: Revista Eletrônica de Geografia, v. 7, n. 19, p. 35-51, 2016.

COSTA, R. G. S.; FERREIRA, C. C. M. Estudo biogeográfico das áreas verdes e da arborização ligada ao sistema viário na região central da cidade de Juiz de Fora (MG). Caminhos de Geografia, v. 8, n. 22, p. 143-153, 2007.

DUARTE, T. E. P. et al. O Papel da Cobertura Vegetal nos Ambientes Urbanos e sua Influência na Qualidade de Vida nas Cidades. Desenvolvimento em Questão, v. 15, n. 40, p. 175-203, 2017. Disponível em: <https://doi.org/10.21527/2237-6453.2017.40.175-203>. Acesso em: 22 dez. 2017.

FARIA, E.; TEIXEIRA, M. Contribuições da Geografia e do Sensoriamento Remoto como ferramenta auxiliar no planejamento espacial do Turismo, um estudo de caso sobre o Parque Nacional da Serra do Cipó-MG. Ciência e Natura, v. 39, n. 2, p. 285-298, 2017. https://doi.org/10.5902/2179460X24158

GOMES, M. F.; QUEIROZ, D. R. E. Avaliação da cobertura vegetal arbórea na cidade de Birigui com emprego de técnicas de geoprocessamento e sensoriamento remoto. Revista Geografar, v. 6, n. 2, p. 93117, 2011. Disponível em: <http://dx.doi.org/10.5380/geografar.v6i2.21579>. Acesso em: 12 dez. 2017.

GOMES, M. A. S.; SOARES, B. R. A vegetação nos centros urbanos: considerações sobre os espaços verdes em cidades médias brasileiras. Estudos Geográficos, v. 1, n. 1, p. 29-39, 2003.

IBGE - Instituto Brasileiro de Geografia e Estatística. 2010. Censo demográfico de 2010. Disponível em: <https://censo2010.ibge.gov.br/sinopse/index.php?dados=210\&uf=35>. Acesso em: 15 jun. 2018.

IBGE - Instituto Brasileiro de Geografia e Estatística. 2017. Projeção populacional para o ano de 2017. Disponível em: <https://cidades.ibge.gov.br/brasil/sp/salto-de-pirapora/panorama>. Acesso em: 07 set. 2017.

LANG, S.; BLASCHKE, T. Análise da paisagem com SIG. São Paulo: Oficina de Textos, 2009.

LIMA, V.; AMORIM, M. C. C. T. A importância das áreas verdes para a qualidade ambiental das cidades. Formação (Online), v. 1, n. 13, p. 139-165, 2011.

LIU, Z.; HE, C.; ZHOU, Y.; WU, J. How much of the world's land has been urbanized, really? A hierarchical framework for avoiding confusion. Landscape Ecology, v. 29, n. 5, p. 763-771, 2014. Disponível em: <https://doi.org/10.1007/s10980-014-0034-y>. Acesso em: 16 dez. 2017.

LOURENÇO, R. W.; SILVA, D. C. C.; SALES, J. C. A. Development of a methodology for evaluation of the remaining forest fragments as a management tool and environmental planning. Ambiência, v. 10, p. 685698, 2014. Disponível em: <https://doi.org/10.5935/ambiencia.2014.03.03>. Acesso em: 11 out. 2017.

MEIRA, R. T.; SABONARO, D. Z.; SILVA, D. C. C. Elaboração de Carta de Adequabilidade Ambiental de uma pequena propriedade rural no município de São Miguel Arcanjo, São Paulo, utilizando técnicas de geoprocessamento. Engenharia Sanitária e Ambiental, v. 21, p. 77-84, 2016. Disponível em: $<$ http://submission.scielo.br/index.php/esa/article/view/133687>. Acesso em 15 ago. 2017.

NERY, C. V. M.; MOREIRA, A. A.; FERNANDES, F. H. S.; ALMEIDA, L. S.; ALMEIDA, R. P. Utilização do modelo linear de mistura espectral e NDVI para avaliação do comportamento de área desmatada no município de rio Pardo de Minas/MG. Caminhos de Geografia, v. 15, n. 49, p. 104-112, 2014.

$\begin{array}{llllll}\text { Caminhos de Geografia } & \text { Uberlândia - MG } & \text { v. 19, n. } 68 & \text { Dez/2018 } & \text { p. 361-371 } & \text { Página } 370\end{array}$


NUCCI, J. C. Qualidade ambiental e adensamento urbano: um estudo de ecologia e planejamento da paisagem aplicado ao distrito de Santa Cecília (MSP). São Paulo: Editora Humanitas, 2001.

OLIVEIRA, R. A.; SILVA, D. C. C.; SIMONETTI, V. C.; STROKA, E. A. B.; SABONARO, D. Z. Proposição de Corredor Ecológico entre duas Unidades de Conservação na Região Metropolitana de Sorocaba.

Revista do Departamento de Geografia, v. 32, p. 61-71, 2016. Disponível em:

<http://dx.doi.org/10.11606/rdg.v32i0.116467>. Acesso em: 18 dez. 2017.

ORTIZ, G. F.; AMORIM, M. C. C. T. Temperatura da superfície da Cidade de Cândido Mota/SP a partir da imagem de satélite Landsat 7. Revista Geográfica de América Central, v. 2, n. 47E, 2011.

SALES, J. C. A.; SILVA, D. C. C.; FERRARI L. T.; BERTAGNA, R.; LOURENÇO, W. R. Avaliação do impacto ambiental causado pelas alterações espaço temporal do uso do solo e da cobertura vegetal utilizando o modelo das cadeias de Markov. Ciência e Natura, v. 38, n. 1, p. 115-124, 2016. Disponível em: <http://www.redalyc.org/articulo.oa?id=467546196010>. Acesso em: 17 dez. 2017.

SIGRH - Sistema Integrado de Gerenciamento de Recursos Hídricos do Estado de São Paulo. Relatório de Situação dos Recursos Hídricos da Bacia Hidrográfica, 2013. Disponível em: http://www.sigrh.sp.gov.br/relatoriosituacaodosrecursoshidricos>. Acesso em: 05 out. 2017.

SILVA, D. C. C. Proposta metodológica para elaboração de um índice espacial de sustentabilidade ambiental aplicado a bacias hidrográficas. Tese (Doutorado em Ciências Ambientais) - Sorocaba: UNESP. 2016.

SILVA, D. C. C.; SALES, J. C. A.; ALBUQUERQUE FILHO, J. L.; LOURENÇO, R. W. Caracterização morfométrica e suas implicações no acúmulo de sedimentos em reservatórios: o caso da represa Hedberg, Iperó/SP. Ra'ega: O Espaço Geográfico em Análise, v. 36, p. 225-245, 2016. Disponível em: $<\mathrm{http}: / /$ dx.doi.org/10.5380/raega.v36i0.42324>. Acesso em: 11 dez. 2017.

SIMONETTI, V. C.; SILVA, D. C. C.; OLIVEIRA, R. A.; SABONARO, D. Z.; ROSA, A. H. Análise da suscetibilidade do solo a processos erosivos do Parque Natural Municipal Corredores de Biodiversidade (PNMCBIO) de Sorocaba (SP). Ra'ega: O Espaço Geográfico em Análise, v. 44, p. 169-180, 2018. Disponível em: <http://dx.doi.org/10.5380/raega.v44i0.48838>. Acesso em: 13 maio 2018.

USGS - United States Geological Survey. Landsat Program. Disponível em: <http://glovis.usgs.gov/>. Acesso em: 17 fev. 2017.

VALLE, I. C.; FRANCELINO, M. R.; PINHEIRO, H. S. K. Mapeamento da fragilidade ambiental na Bacia do Rio Aldeia Velha, RJ. Floresta e Ambiente, v. 23, n. 2, p. 295-308, 2016. Disponível em: $<$ https://doi.org/10.1590/2179-8087.107714>. Acesso em: 10 dez. 2017.

Recebido em: 28/12/2017

Aceito para publicação em: 12/07/2018 